\title{
Caminhos para a divulgação de Ciência
}

Jussara Mangini

Jornalista, especialista em Gestão da Comunicação, assistente da Gerência de Comunicação da FAPESP.

E-mail: jmangini@fapesp.br

Resumo: Com 23 anos de carreira, a jornalista Jussara Mangini compartilha aprendizados adquiridos em 12 anos de divulgação de Ciência em diferentes instituições públicas - Universidade Federal de São Paulo (Unifesp), onde coordenou a assessoria de imprensa de 1999 a 2003, Universidade Federal do ABC (UFABC), que foi seu objeto de estudo na especialização em Gestão da Comunicação na ECA/USP, concluída em 2007, e atualmente na Fundação de Amparo à Pesquisa do Estado de São Paulo (FAPESP), onde é assistente da gerência de comunicação desde 2009. Ela também fala sobre a propagação de sites e blogs de Ciência como alternativa ao encolhimento dos espaços editoriais sobre o tema na mídia tradicional. Essa tendência mundial tem se consolidado como uma oportunidade de atuação profissional e de ampliação de público.

Palavras-chave: jornalismo, ciência, gestão, instituição pública, produção científica.
Abstract: With 23 years of career, the journalist Jussara Mangini shares learnings acquired in 12 years of promotion of science in different public institutions - Universidade Federal de São Paulo (Unifesp) where was in charge of press office from 1999 to 2003, Universidade Federal do $A B C$ (UFABC), which was her object of study in specialization in Communication Management at ECA/USP completed in 2007, and currently in the Sao Paulo Research Foudantion (FAPESP), where is an assistant of the communication management. She also talks about the spread of websites and blogs of science as an alternative to shrinking spaces editorial on the subject in traditional media. This global trend has been established as an opportunity to professional practice and public magnification.

Keywords: journalism, science, management, public institution, scientific production.

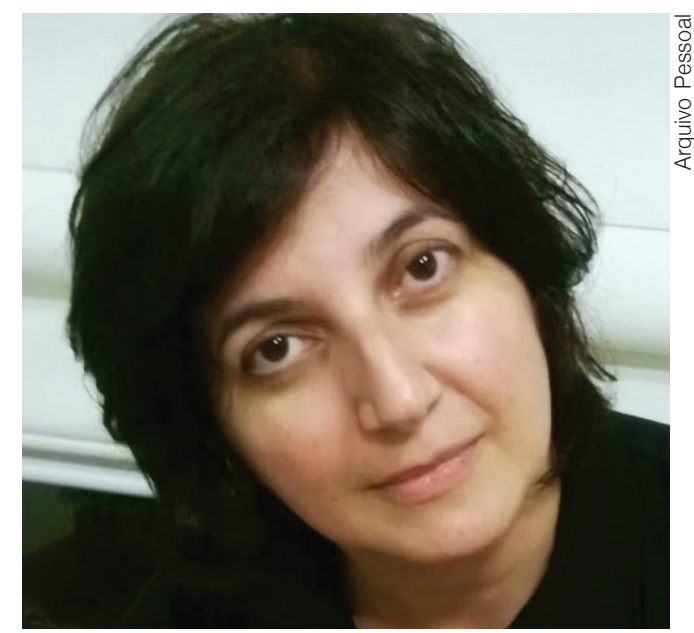

Recebido: 28/02/2015

Aprovado: 25/03/2015 
comunicação \& educação • Ano XX • número 1 • jan/jun 2015

\section{UM MAR DE CURIOSIDADES}

Em 1977, aos oito anos de idade, mudei-me com minha família de Mogi das Cruzes, na região metropolitana da capital paulista, para Santos, litoral sul de São Paulo. Na primeira noite no novo lar, conhecemos o impacto de um mar revolto na cidade. Já tinha visto enchentes provocadas pelo rio Tietê, mas ruas inundadas de água salgada, nunca. A água invadiu o quintal do apartamento térreo e quase entrou na casa. "O mar está de ressaca", diziam os vizinhos a nós, os forasteiros recém-chegados. Fiquei assustada e queria entender por que o mar ficava descontrolado quando estava de ressaca. Seria perigoso viver naquele lugar? Não queria me decepcionar, já que tinha criado tantas expectativas positivas sobre o que seria "morar na praia". Não percebia que, mais do que o mar lá fora, o que me inquietava era um mar de curiosidades em mim - e que as respostas disponíveis à época já não conseguiam mais conter.

Os adultos me diziam que "aqui é assim, às vezes o mar fica bravo e avança sobre a cidade”. As respostas eram insatisfatórias, mas não existia internet nem Google para consultar. E, antes mesmo de encontrar algum livro naquela bagunça da mudança, encontrei outra fonte de inquietação. Enquanto ajudava a esvaziar as caixas, deparei-me com uma foto dos meus pais em uma praia belíssima. Eles estavam ao lado de uma grande rocha. Minha mãe me contou que era possível ouvir o som de sinos dentro dela. Fiquei intrigadíssima e questionava: como era possível?

Minha mãe se referia à Pedra do Sino, uma formação rochosa da praia de Garapocaia, em Ilhabela, no litoral norte de São Paulo. Há comerciantes que oferecem martelos aos milhares de turistas que visitam o local na alta temporada para que eles batam nas rochas e escutem o som metalizado semelhante ao dos sinos de igreja. Uma lenda local diz que, em uma manhã do século XVII, o soar de sinos acordou o povoado da ilha de São Sebastião em tempo de se defender de piratas que tinham atracado seu navio na ilha e estavam prestes a iniciar um ataque. Sob o comando do guerreiro São Sebastião, a população expulsou os intrusos e a calmaria se restabeleceu. Quem descobriu que o som de sinos vinha das rochas da praia foram os índios. Mas ninguém sabia explicar por que a pedra emite essa sonoridade.

A narrativa das lendas é um recurso sedutor para manter vivo o mistério. Mas a desinformação pode ser destruidora. Se a propagação do som na Pedra do Sino estiver mesmo relacionada com a compacidade e formação do bloco rochoso e com seus pontos de apoio, como apontam alguns estudos, é possível que a produção do som venha a ser afetada pelo costume de bater na rocha. É que essa prática, feita repetidamente, geralmente com força e por muitas pessoas, pode levar a rachaduras ou quebra de pedaços da rocha.

Não. Não descobri isso na infância. Descobri recentemente, buscando inforO patrimônio geológico de Ilhabela - SP: estratégias de conservação. Instituto de Geociências, USP, 2014. mações sobre Ilhabela, quando me deparei com uma dissertação de mestrado apresentada no Instituto de Geociências da USP ${ }^{1}$. As (muitas) inquietações da minha infância não me levaram diretamente pelos caminhos da Ciência, 
mas o contato com a divulgação científica resgatou velhos questionamentos e, finalmente, ajudou a saná-los.

Ler trabalhos científicos passou a fazer parte da minha rotina desde que comecei a trabalhar com divulgação científica. Sou jornalista há 23 anos e, depois de experimentações em jornalismo diário, comunicação corporativa, ONGs, revistas especializadas em vários segmentos de mercado, passei a divulgar para a sociedade o conhecimento produzido em universidades e centros de pesquisa.

Sem formação específica, iniciei um novo e rico processo de aprendizado em um ambiente muito propício para adquirir conhecimento: a Universidade Federal de São Paulo (Unifesp), onde trabalhei durante seis anos, de 1997 a 2003 no Departamento de Comunicação, sendo os quatro últimos como coordenadora da Assessoria de Imprensa. Em 2006, depois de passar por uma organização que agrupava ONGs com forte atuação em educação, aceitei o convite da Universidade Federal do ABC (UFABC). Na época a universidade experimentava diariamente um massacre da imprensa e do setor produtivo local, afinal com sua proposta pedagógica inovadora, permeada por valores e ideais que visam à formação integrada de cidadãos preparados para construir conhecimento, não correspondia com a expectativa daqueles que esperavam da universidade apenas formação de mão-de-obra altamente qualificada. Não tive dúvidas em escolher a UFABC como meu objeto de estudo no curso de especialização em Gestão da Comunicação, da ECA/USP, que concluí em 2007. Na sequência vieram dois anos dedicados à produção de relatórios de sustentabilidade para grandes empresas até que surgisse a oportunidade de estar novamente em contato com o mundo acadêmico e da produção científica, na Fundação de Amparo à Pesquisa do Estado de São Paulo (FAPESP), uma das principais agências de fomento à pesquisa científica e tecnológica do país, onde trabalho há quase seis anos.

\section{INTERESSE PELA CIÊNCIA: A ORIGEM}

É possível que a origem dessa vocação tenha surgido ainda na infância sob a influência de professores incríveis e também porque tinha em casa uma audiência especialmente interessada. Quando ainda estava no ensino fundamental (chamava-se primário) eu compartilhava com minha mãe tudo o que aprendia na escola. Mas o que a levava a interromper as atividades domésticas para me ouvir com atenção era o conteúdo das aulas de Ciência, especialmente sobre planetas do Sistema Solar.

Talvez esse interesse, meu e dela, também tenha sido influenciado pelo bombardeio de ficção científica que as gerações dos anos 1970 e 1980 assistiram na TV e no cinema: de desenhos animados como The Jetsons e as séries Os invasores, Perdidos no espaço, Túnel do tempo a filmes como Flash Gordon, Planeta dos macacos, Star wars, entre outros.

Ficção e lendas à parte, eu só obtive a resposta para o que causa ressaca no mar com a professora Marcia, que lecionava Ciência para a $5^{\mathrm{a}}$ série da Escola 
Estadual Zina de Castro Bicudo, em São Vicente, cidade vizinha de Santos. Foi a professora Marcia que me apresentou a Teoria da Evolução, de Charles Darwin. Também foi ela quem fez com que eu, aos 12 anos, começasse a ler a editoria de Ciência e Tecnologia da extinta revista Manchete e a folhear o caderno de Cultura do jornal O Estado de S. Paulo. Uma edição "gorda" de domingo, no início dos anos 1980, trouxe um especial sobre Darwin que me ajudou a tirar nota "A" nessa disciplina, com um trabalho que a professora guardou consigo.

Está aí um exemplo de que a imprensa pode cumprir com louvor seu papel de divulgadora de Ciência, conforme propõe a Espiral da Cultura Científica ${ }^{2}$, uma representação gráfica que demonstra as categorias e atores envolvidos na dinâmica da circulação do conhecimento científico, criada pelo professor Carlos Vogt, ex-presidente da FAPESP e responsável pelo Laboratório de Estudos Avançados em Jornalismo (Labjor) da Universidade Estadual de Campinas (Unicamp).

Trabalhar com divulgação científica é especialmente enriquecedor porque é uma prática que nos desafia a aprender constantemente e a exercitar a capacidade de traduzir informações complexas para uma linguagem acessível a públicos não especializados, com reponsabilidade e precisão.

Mesmo quando o jornalista desenvolve suas preferências em temas que tem mais facilidade ou interesse, conhecer o percurso que levou o cientista a uma descoberta é quase sempre surpreendente.

Sem falar no poder transformador do raciocínio científico. Se pessoas e empresas adotassem a lógica científica poderiam encontrar soluções mais efetivas para seus dilemas: a partir de um problema ou dúvida elaboram-se hipóteses a respeito de suas causas e efeitos sem se valer do "achismo". Inicia-se um levantamento sobre o que já se sabe sobre esse tipo de problema ou situação análoga. Com essas informações, define-se um plano de ação que tem de seguir uma metodologia (escolha de técnicas, tipo de amostra, ambiente, tipo de testes) mais adequada para obter os dados que, após serem analisados e comparados, ajudarão a chegar a conclusões. Essas conclusões podem ser inéditas ou simplesmente confirmarem tudo o que já se sabia a respeito. Também podem surgir novas dúvidas que motivarão a continuar buscando respostas

para velhas perguntas.

2. VOGT, Carlos. A Espiral da Cultura Científica. Boletim de Ideias n. 3. FAPESP.

\section{O COMPETITIVO E CONTROVERSO UNIVERSO DA CIÊNCIA}

Sem conhecer e compreender as etapas do processo de produção científica e suas regras e regulamentações - gerais e específicas de cada área, o jornalista pode cometer muitos erros. Se, na ânsia pela notícia ou pelo furo de reportagem, a investigação e o cuidado com a checagem de detalhes e controvérsias - aspecto intrínseco à Ciência - forem postos em segundo plano, o jornalista pode disseminar um engodo, do ponto de vista científico, mas também jornalístico. 
Pesquisadores são bastante pressionados a dar publicidade aos resultados de seus experimentos, afinal não faz sentido o cientista guardar o resultado de suas pesquisas para si. É por meio do artigo científico que ele compartilha descobertas com a comunidade acadêmica e, assim, contribui com a expansão do conhecimento.

Em Ciência, o crédito vai para o cientista que primeiro apresenta uma ideia para o mundo, e não necessariamente para aquele que a teve primeiro. A publicação científica, nesse sentido, tem a função de registro histórico, sobretudo para as pesquisas que inicialmente não resultam em patentes. Publicar um artigo científico consistente é uma forma eficiente de garantir a precedência e a originalidade da pesquisa científica realizada.

A produção de um pesquisador é medida pelo número de artigos científicos de sua autoria publicados em revistas científicas nacionais e estrangeiras e pela citação de seu trabalho feita por outros cientistas em artigos escritos por eles. A produção é avaliada, também, pela qualidade das revistas onde os artigos são publicados. Há organizações especializadas em avaliar a qualidade das revistas, as chamadas bases indexadoras, como a SciELO, que dá acesso gratuito a textos completos. Há também organizações especializadas em consolidar dados sobre produção científica de países e de universidades em rankings mundiais. Estar bem posicionado em determinados rankings é meta perseguida por universidades e nações.

Artigos científicos são, portanto, uma importante matéria-prima para a imprensa de Ciência. Porém, é importante saber que nem mesmo o fato de o artigo ter sido aceito em uma revista científica, que tem critérios próprios de crivo e aprovação, garante que o estudo é confiável ou preciso.

Por um lado, é preciso considerar que todo cientista é um ser humano e, como tal, sujeito a falhas. Algum erro conceitual ou metodológico pode passar despercebido durante a pesquisa, ou até mesmo as conclusões formuladas podem ser equivocadas.

Por outro lado, têm sido mais frequentes denúncias e constatações de fraudes em pesquisas. Tal realidade levou a FAPESP, por exemplo, a lançar seu Código de Boas Práticas e a criar uma comissão para avaliar as denúncias relacionadas às pesquisas que apoia financeiramente.

Alguns cuidados são recomendados como antídoto para não comprar e nem vender gato por lebre. É importante cavar mais fundo os dados do material recebido, farejar contradições, cultivar relações com a comunidade de pesquisa, não confiar em uma única fonte, ter sempre uma segunda opinião, ouvir atentamente o que diz e como diz a fonte. Também vale o cuidado com uma possível "fonte de desinformação": as estatísticas falsas ou enganosas. O ideal é pedir à fonte que mostre os números absolutos - e nunca aceitar a porcentagem. Um aumento de $10 \%$ pode parecer muito, mas se for apenas três pessoas, esqueça, é apenas um ruído. Dicas como essas podem ser obtidas em cursos on-line oferecidos pela World Federation of Science Journalists (WFSJ) em parceria com o SciDev.Net ${ }^{3}$.
3. Online Course in Science Journalism. Disponível em: <http://www.wfsj. org/course/index-e.html>. Acesso em: 19 fev. 2015. 


\section{MEDIANDO A RELAÇÃO JORNALISTA X CIENTISTA}

Quando eu ingressei na assessoria de imprensa da Unifesp completei uma equipe de três pessoas. Alguns anos depois chegamos a uma equipe de cinco para atender a demanda de 21 departamentos acadêmicos que somavam 83 disciplinas. Naquela época, a universidade - que nasceu Escola Paulista de Medicina em 1933 e tinha sido federalizada em 1995 - ainda era voltada exclusivamente para a formação nas áreas de saúde, com cinco cursos de graduação - Medicina, Enfermagem, Biomedicina, Tecnologia Oftálmica e Fonoaudiologia - e 34 programas de pós-graduação.

Internet ainda era novidade. Contávamos com dois catálogos impressos, um de docentes e outro do corpo clínico do Hospital São Paulo (hospital universitário da Unifesp) para saber quem era quem em cada disciplina ou laboratório. Aos poucos fomos levantando quais eram as doenças que cada um pesquisava ou tratava.

Diariamente, recebíamos muitos pedidos de entrevista. Vivíamos num fogo cruzado - de um lado jornalistas se queixavam de que os docentes da Unifesp e médicos do Hospital São Paulo precisavam de media training; de outro, as fontes se queixavam da falta de repertório dos jornalistas sobre assuntos da área de saúde.

Lembro-me de um professor que desistiu de prosseguir com uma entrevista porque o repórter não sabia a diferença entre vírus e bactéria. Outro foi bem pouco gentil quando alguém lhe perguntou o que era um banco óptico, expressão que ele usou durante a entrevista. Ele considerava aquilo uma obviedade para qualquer pessoa. Apesar de serem profissionais brilhantes, eu não compreendia porque, sendo professores, eles relutavam tanto em ser didáticos com leigos. Depois compreendi que, para alguns, falar com a imprensa era perda de tempo e a única divulgação que valorizavam era por meio dos artigos científicos nas revistas especializadas. Felizmente, também contávamos com professores conscientes e sensatos.

Ainda assim, no dia-a-dia, parte do tempo da assessoria de imprensa era dedicada a conscientizar professores de que atender a imprensa era uma forma de compartilhar conhecimento com a sociedade, além de uma forma de prestar contas sobre o resultado obtido com apoio de recursos públicos. Outra parte do tempo era dedicada a ajudar a mídia a compreender dados de pesquisas ou tratamentos médicos, com todo suporte necessário para a produção de notícias sobre saúde.

Percebemos que a experiência adquirida com as orientações e com a mediação diária da relação jornalista-cientista, nos gabaritava a estruturar e institucionalizar um curso sobre saúde para jornalistas. O objetivo era qualificar a cobertura da mídia e, ao mesmo tempo, estreitar as relações entre as fontes da universidade e jornalistas. Convidamos professores de diversas disciplinas. Alguns prepararam aulas específicas sobre suas especialidades médicas e outros abordaram aulas sobre questões conceituais, históricas e jurídicas sobre as ciências 
da saúde. Foi um grande aprendizado para quarenta jornalistas, eu inclusive. Tenho certeza que, depois da aula de epidemiologia clínica, todos aprenderam a diferenciar endemia de epidemia ou de pandemia, ou ainda incidência de prevalência, entre outros conceitos fundamentais que, se usados incorretamente em uma notícia, geram um grande desserviço. Mais do que isso, foi uma aula que nos ensinou a perceber falhas metodológicas em estudos na área de saúde e, com isso, ter uma percepção mais apurada para identificar estudos sérios.

Outro grande desafio era fazer gestores de áreas-chave, especialmente do Hospital São Paulo, de que a área de Comunicação da universidade não podia ser a última a saber de novidades ou sobre os inúmeros problemas relacionados ao funcionamento do hospital. Fizemos um workshop para mostrar como a comunicação poderia ser útil e estratégica para prevenir situações de crise, ou amenizar seus efeitos na imagem institucional.

Resistências à parte, para nossa alegria, em certa ocasião, o diretor do hospital provou que havia aderido às nossas recomendações. Ele pediu que convocássemos a imprensa para anunciar que o hospital amanheceria de portas fechadas. Ele queria que a população fosse avisada em primeira mão, na véspera, e informada sobre os motivos da crise que impedia a abertura a atendimentos não emergenciais. A imprensa compreendeu os motivos e as reportagens, em vez de tom de ataque, foram esclarecedoras. Foi muito especial ver que havíamos conquistado a confiança da direção do hospital e ver a população sendo alertada em primeira mão. Longe de ser uma solução, um mínimo gesto de respeito.

Em parte, isso também resultou da relação de credibilidade que a assessoria de imprensa da Unifesp construiu com a imprensa. Realizávamos um trabalho ágil, preciso e transparente que buscava facilitar ao máximo o trabalho dos jornalistas que nos consultavam.

Quando sabíamos que a fonte da Unifesp não era a mais indicada para abordar o assunto que estava sendo solicitado, éramos francos e, muitas vezes, indicávamos nome e telefone de profissionais de outra instituição. Passamos a ser uma referência. Alguns colegas brincavam conosco dizendo: "essa assessoria é uma mãe”. Nossas indicações tinham respaldo de orientações da reitoria, que passou a nos receber semanalmente para contar boas novas ou nos alertar sobre "focos de incêndio" que poderiam se alastrar para a imprensa sem nosso controle. Nesses encontros, ele também contextualizava o cenário político no âmbito da saúde, sempre dando uma aula sobre o funcionamento do Sistema Único de Saúde (SUS). Preocupava-se, ainda, em apontar o que estava no Estado da Arte na Unifesp, em relação a outros centros de pesquisa, e o que ainda estava apenas engatinhando.

\section{PESQUISAS DISPUTADAS PELA IMPRENSA}

A exposição da Unifesp na mídia era grande e diversificada, mas limitada à divulgação de eventos, novos serviços de atendimento médico, campanhas, 
cursos etc. O tipo de inserção que obtínhamos eram notas, chamadas em rádios, pequenas matérias. Matérias mais expressivas surgiam por iniciativa da imprensa. Para dar uma visibilidade mais relevante era necessária uma atuação mais proativa na proposição de pautas sobre as pesquisas desenvolvidas na Unifesp.

O Jornal da Paulista (JP), publicação mensal da Unifesp, produzia cerca de dez reportagens sobre resultados de pesquisa. Eram pautas muito interessantes, com notícias bem escritas e editadas por um ex-repórter de Ciência da Folha de S.Paulo e estudante de medicina na Unifesp. Quando o jornal chegava às redações, os editores sabiam que a concorrência também estava recebendo o material. Nem sempre aproveitavam o conteúdo porque queriam exclusividade.

Decidi usar as notícias do JP como um produto diferenciado, oferecido em primeira mão para os veículos que poderiam ter melhor aproveitamento do material. Cerca de dez dias antes de o jornal ser distribuído, eu fazia um resumo da pauta em cerca de dez linhas e incluía no rodapé as possibilidades de imagens, personagens e entrevistas.

Previamente, eu consultava a agenda dos autores da pesquisa para saber se estariam disponíveis para entrevistas, assim como consultava os pacientes indicados por eles sobre a disponibilidade de atender a imprensa. Resumindo, eu fazia todo o trabalho de pré-produção para que o editor soubesse de todas as possibilidades e decidisse rapidamente se interessava ao veículo a chance de sair na frente dos demais. A proposição de pautas prosseguia até a data da distribuição do jornal.

Há 15 anos essa foi a estratégia que fez as pautas do Jornal da Paulista serem disputadas pela grande imprensa. Conquistamos um salto quanti-qualitativo muito positivo que somava-se à repercussão dos programas da TV Unifesp e notícias da revista Saúde Paulista. Sem dúvida, levamos informação de qualidade para além dos muros da academia.

Atualmente, em outro ambiente e em tempos de jornalismo on-line, monitoro a repercussão das notícias publicadas na Agência FAPESP. Diariamente centenas de veículos reproduzem seu conteúdo, total ou parcialmente, resultando numa média anual de 5 mil notícias em todo o país. Sem contar a repercussão do trabalho da assessoria de imprensa e da revista Pesquisa FAPESP, que elevam as citações à FAPESP na mídia nacional e internacional a mais de 10 mil notícias por ano

Essas estatísticas são fruto de um dos trabalhos que realizo na FAPESP. Quando cheguei, em 2009, identifiquei uma lacuna: não havia um processo sistemático de monitoramento, mensuração e análise do trabalho realizado. Hoje, produzo levantamentos estatísticos e analíticos que subsidiam o gestor de comunicação na tomada de decisões e ajudam a demonstrar a efetividade do trabalho da Comunicação para a instituição. Além disso, dedico meses à produção editorial do Relatório Anual de Atividades da FAPESP, por meio do qual é feita a prestação de contas sobre a aplicação dos recursos públicos no apoio a pesquisas científicas, e escrevo esporadicamente para a Agência FAPESP. 


\section{QUANDO OS FINS ELIMINAM OS MEIOS}

Embora a área de Comunicação esteja presente em organogramas e em espaços físicos nas instituições do sistema público de Educação e C\&T, não há compreensão nem disposição para tentar entender as especificidades do jornalismo em suas necessidades de infraestrutura e de recursos humanos, dificultando, assim, contratações de profissionais com perfil à altura da demanda e expectativa dos gestores.

A sustentabilidade de projetos de comunicação - tradicionais ou inovadores - depende de uma percepção firme da alta gestão, áreas administrativas, RH e público interno sobre a importância de uma política de comunicação no aprimoramento de suas atividades-fim, seja pesquisa, fomento à pesquisa ou atendimento médico, entre outros.

Foi com a finalidade de reduzir despesas que o serviço de divulgação científica da Unifesp foi terceirizado. Por razões que desconheço, não existem mais registros físicos nem digitalizados dos produtos de comunicação daquele período nem mesmo para constar como parte da memória institucional.

Restam registros pessoais de quem passou por lá como a fotografia ${ }^{4}$ que guardo com carinho da entrevista com Dr. Ricardo Smith, professor de Anatomia Descritiva e Topográfica. Dr. Smith (percebam a coincidência com o nome do personagem de um dos filmes que assistia lá na infância) é dessas figuras raras da medicina que ainda se interessam por questões humanistas. Tanto é que estudou psicanálise e desenvolveu um curso de Psicodrama em Anatomia para ajudar colegas a superarem conflitos em relação à morte.

Ele me deu uma explicação filosófica para compreender porque os jovens estudantes de medicina, que chegam para lidar com a vida, vão logo lidar com a morte, na aula de anatomia, que é ministrada no primeiro e terceiro anos do curso. Segundo ele, "na juventude a vida é quente, efervescente. A aula de anatomia serve para esfriar um pouco essa sensação. Para lidar bem com a realidade de um pronto-socorro, por exemplo, um médico tem de estar com a cabeça fria, compenetrado, equilibrado emocionalmente. Do contrário, imagine como reagiria a cada veia que visse jorrando sangue”. Essa conversa está registrada na reportagem "Lição de Respeito", ilustrada por uma obra de Rembrant - Lição de Anatomia do Dr. Tulp ${ }^{5}$, na sexta edição da revista Saúde Paulista, em 2002.

Essa e outras histórias de bastidores da notícia, com desfechos surpreendentes, estão na minha memória e poderiam exemplificar bons e maus casos da prática jornalística.

\section{MUDANÇAS E OPORTUNIDADES NA DIVULGAÇÃO DE CIÊNCIA}

Duas reportagens que produzi sobre a Conferência Mundial de Jornalistas de Ciência ${ }^{6}$, realizada na Finlândia em 2013, ajudam a compreender o impacto
4. Mudanças e oportunidades no jornalismo científico. Agência FAPESP. Disponível em: $<$ http://agencia.fapesp.br/ mudancas_e_oportunidades_no_jornalismo_cientifico/17649/>. Acesso em: 19 fev. 2015.

5. A Conexão Digital. Revista Pesquisa FAPESP. ed. 211. Setembro de 2013. Disponível em: < http://revistapesquisa. fapesp.br/2013/09/12/a-conexao-digital>. Acesso em: 19 fev. 2015.

6. Mudanças e oportunidades no jornalismo científico. Agência FAPESP. Disponível em: <http://agencia.fapesp.br/ mudancas_e_oportunidades_no_jornalismo_cientifico/17649/>. Acesso em: 19 fev. 2015. 
da crise do jornalismo mundial na cobertura de Ciência e aponta alternativas para driblar a crise.

Nelas, observo que, com a diminuição de espaços reservados à cobertura de temas de Ciência nos grandes veículos, as plataformas digitais vêm se consolidando como espaço de divulgação científica para jornalistas e para cientistas. Sites e blogs de Ciência têm permitido aumentar não apenas o público leitor, mas também a participação das pessoas na construção e discussão dos assuntos de Ciência.

Essas mídias também criam a oportunidade de explicar Ciência de forma mais atrativa, especialmente para o público jovem. A recomendação de jornalistas que participaram como debatedores no evento, é que o profissional deve conjugar boas práticas do jornalismo com habilidades multimídia e criatividade, ou seja, dominar ferramentas tecnológicas e linguagens como vídeo, podcast, fotografia, charges, infográfico, história em quadrinhos, poesia, música, ficção científica.

Também é importante compreender que na lógica da blogosfera, a moeda de confiança e reputação é o hiperlink. Assim como a comunidade científica cita seus pares em artigos científicos, o texto on-line, sobretudo na cobertura de temas ligados à pesquisa, deve fazer ligações com todos os documentos e referências mencionadas. Mesmo que a maioria dos leitores não tenha tempo para abrir todos os links, eles são a prova de que o autor fez a diligência de pesquisar dados e fontes relevantes. Ou seja, sem critério, de nada adiantam gadgets e aplicativos. 